aboratorium voor Moleculaire Celbiologie, Katholieke Universiteit te Leuven, Kardinaal Mercierlaan 92, B-3001 Leuven-Heverlee, Flanders, Belgium

\section{Constitutive glucose-induced activation of the Ras-CAMP pathway and aberrant stationary- phase entry on a glucose-containing medium in the Saccharomyces cerevisiae glucose- repression mutant hex2}

\author{
Françoise Dumortier, Juan-Carlos Argüelles† \\ and Johan $M$. Thevelein \\ Author for correspondence: Johan M. Thevelein. Tel: $+3216321507 / 321500$. \\ Fax: +3216321979 .
}

Addition of glucose to cells of the yeast Saccharomyces cerevisiae growing on a nonfermentable carbon source triggers a rapid, transient increase in the CAMP level. The occurrence of this CAMP spike appears to be correlated inversely with the glucose-repression state of the cells. This was also observed for the hex2 mutant, which is deficient in glucose repression and which displayed the CAMP signal constitutively. When cells of the hex2 mutant were starved for nitrogen on a glucose-containing medium, they rapidly lost viability, similarly to mutants with overactivation of the Ras-adenylate cyclase pathway. Flow cytometry measurements showed that $G_{1}$ arrest of the hex2 mutant under such conditions was incomplete. Trehalose accumulation, a typical feature of cells entering the stationary phase $\mathbf{G}_{0}$, was very short-lived in the hex2 mutant under the same conditions. These results are in agreement with the presence of continuous glucose-triggered activation of CAMP synthesis in hex2 cells on a glucose-containing nitrogen-starvation medium. In the course of these experiments a spontaneous suppressor mutant, shx (for suppressor of hex2), was isolated which survived nitrogen starvation on a glucose-containing medium much better than the hex2 strain. It also showed normal $G_{1}$ arrest and much longer accumulation of trehalose. The suppressor mutation also caused inability to grow on nonfermentable carbon sources and absence of invertase derepression, and it was epistatic to hex2 for these characteristics also. The isolation of this epistatic derepression mutation supports the idea that the defect in glucose repression of the hex 2 mutant is the cause of its rapid loss of viability during nitrogen starvation on a glucosecontaining medium. Substitution of glucose for glycerol partially abolished the rapid loss of viability in the hex 2 mutant. These results suggest that the glucose-repressible character of the pathway involved in glucose-triggered activation of CAMP synthesis might have a physiological role in preventing overstimulation of CAMP synthesis and allowing proper entrance into the stationary-phase $\mathbf{G}_{0}$ in a medium containing ample glucose but lacking another essential nutrient for growth. Such a situation might be quite common in the glucose-rich natural environment of S. cerevisiae.

Keywords: yeast, signal transduction, nitrogen starvation, cell cycle, glucose-sensing

†Present address: Universidad de Murcia, Facultad de Biologia, Departamento de Genetica y Microbiologia, 30071 Murcia, Spain. Abbreviation: CAPK, CAMP-dependent protein kinase. 


\section{INTRODUCTION}

In the yeast Saccharomyces cerevisiae, the synthesis of cAMP is controlled by an elaborate regulatory pathway (for recent reviews see Broach \& Deschenes, 1990; Thevelein, 1991, 1992; Tatchell, 1993). The main components known in this pathway are adenylate cyclase, which is controlled by the Ras1 and Ras 2 proteins (Toda et al., 1985), the GDP/GTP exchange factor of the Ras proteins, Cdc25 (Camonis et al., 1986), and the Ras-GTPase activating proteins, Ira1 and Ira2 (Tanaka et al., 1989, 1990). cAMP causes activation of cAMP-dependent protein kinase (cAPK), which is composed of catalytic subunits encoded by the genes TPK1, TPK2 and TPK3 (Toda et al., 1987b) and regulatory subunits encoded by the gene $B C Y 1$ (Toda et al., 1987a). The PDE1 and PDE2 genes encode the two phosphodiesterase enzymes which are responsible for cAMP hydrolysis (Sass et al., 1986; Nikawa et al., 1987b). Another major factor downregulating cAMP synthesis is feedback inhibition by cAMP-dependent protein kinase (Nikawa et al., 1987a). By analogy with the signalling function of the Ras proteins and other G-class proteins in mammalian cells, the yeast Ras-adenylate cyclase pathway is also considered to function as a signalling pathway. However, the actual signalling function of the yeast Ras pathway is not well understood.

Only two stimuli, fermentable sugars and intracellular acidification, have clearly been identified as potent stimulators of Ras-pathway-dependent cAMP synthesis in vivo (reviewed by Thevelein, 1991, 1992). Glucose and related fermentable sugars cause a Ras-dependent rapid, transient increase in the cAMP level ('cAMP signal') when added to cells growing on a nonfermentable carbon source, such as glycerol or ethanol, or to stationary-phase cells deprived of glucose (Thevelein \& Beullens, 1985; Mbonyi et al., 1988). Intracellular acidification triggered for example by protonophore addition at low extracellular $\mathrm{pH}$ causes a much larger cAMP increase in the same cell types but also in cells growing exponentially on glucose (Thevelein et al., 1987; Argüelles et al., 1990). Glucoseinduced stimulation of cAMP synthesis, on the other hand, is largely absent in cells growing exponentially on glucose. This is apparently related to the glucoserepression state of the cells (Beullens et al., 1988; Argüelles et al., 1990). In yeast cells growing exponentially on glucose, a large number of genes involved in respiration, gluconeogenesis, transport and catabolism of alternative carbon substrates and other processes are repressed. An extensive number of mutants deficient in glucose repression, e.g. $b \times k 2$ and $b e \times 2$, or deficient in derepression, e.g. cat $1 /$ snf1 and cat $3 /$ snf4, have been isolated and characterized (for recent reviews see Entian \& Barnett, 1992; Johnston \& Carlson, 1992). The glucoserepression-deficient mutant $b \times k 2$ displays a glucoseinduced cAMP signal also in cells growing on glucose, while mutants unable to show derepression, cat $1 /$ snf1 and cat $3 /$ snf 4 , do not show a glucose-induced cAMP signal either in stationary-phase cells or in cells growing on glucose. Acidification-induced cAMP synthesis, on the other hand, can be triggered in all cell types, also in the derepression mutants (Beullens $e t$ al., 1988; Argüelles $e t$ al., 1990). A tentative explanation for these observations is the presence of a glucose-repressible protein in the glucose-triggered activation pathway of Ras-adenylate cyclase, upstream of the point where it is triggered by intracellular acidification (Thevelein, 1991). Such a protein, however, has not been identified yet.

The functioning of glucose as a stimulator of the Rasadenylate cyclase pathway is consistent with the observation that upon addition of glucose to cells grown on a nonfermentable carbon source, several enzymes and processes are activated or inactivated which are known to be regulated by cAMP-dependent protein phosphorylation (reviewed by Thevelein \& Hohmann, 1995). Cells growing exponentially on glucose also display the same set of phenotypic characteristics as mutants with elevated cAMP levels or cAPK activity, e.g. low trehalose and glycogen levels, low heat resistance, and low expression of heat-shock protein genes and other genes, such as CTT1 and UBI4. However, if cells are starved on a glucose-containing medium for any other essential nutrient, they arrest in the $G_{1}$ phase of the cell cycle, accumulate in $G_{0}$ and acquire all properties which are typical of mutants with a low level of cAMP or low activity of cAPK in spite of the continuous presence of glucose (Lillie \& Pringle, 1980; Bissinger et al., 1989; Hirimburegama et al., 1992; Werner-Washburne et al., 1993). Apparently, under such conditions glucose is unable to stimulate cAMP synthesis or at least not to such an extent that the phenotype resembles the high-cAMP phenotype. Yeast cells that are starved on a glucosecontaining medium for another essential nutrient remain glucose-repressed. Therefore, the presence of a glucoserepressible protein in the glucose-induced activation pathway of cAMP synthesis would explain the absence of stimulation of cAMP synthesis under conditions where ample glucose is present but another essential nutrient is lacking. Since it has been demonstrated that other essential nutrients are able to cause similar activation of enzymes and processes as glucose or high cAMP, but in a noncAMP-dependent way, for instance in cells lacking the regulatory subunit of cAPK (Thevelein \& Beullens, 1985; Cameron et al., 1988; Belazzi et al., 1991; Durnez et al., 1994), we have proposed that a novel nutrient-induced pathway activates directly the free catalytic subunits of cAPK (Thevelein, 1991). This pathway, which we recently called the "fermentable-growth-medium-induced pathway' (Thevelein \& Hohmann, 1995) would be responsible for the 'high-cAPK phenotype' during growth on glucose, while the glucose-induced activation pathway of cAMP synthesis would be responsible for the stimulation of the transition from gluconeogenic/ respiratory growth to fermentative growth. The function of the glucose-repressible character of the latter pathway would be to prevent stimulation of cAMP synthesis in cells which are deprived of an essential nutrient in a medium containing glucose.

In the present paper we show that the glucose-repression mutant bex2 displays characteristics of a high-cAMP phenotype when starved for nitrogen on a glucosecontaining medium, which is consistent with this idea. 
The bex 2 mutant is not only deficient in glucose repression but shows a pleiotropic phenotype. One distinctive feature is its inability to grow on maltose when a constitutive $M A L$ gene is present. This is apparently due to misregulation of maltose uptake (Entian, 1980). The Hex 2 protein is located in the nucleus, possibly indicating a direct role in the control of transcription (Niederacher \& Entian, 1991). The bex2 mutation was also isolated as a second-site suppressor ( $s r n 1$ ) of a mutation affecting RNA processing, but the mechanism involved is unclear (Tung et al., 1992).

\section{METHODS}

Yeast strains and growth conditions. The Saccharomyces cerevisiae strains used in this study are shown in Table 1 . The cells were grown in YPD $(1 \%, w / v$, yeast extract, $2 \%, w / v$, bactopeptone, $2 \%, \mathrm{w} / \mathrm{v}$, glucose) or YPG $(1 \%, \mathrm{w} / \mathrm{v}$, yeast extract, $2 \%, \mathrm{w} / \mathrm{v}$, bactopeptone, $3 \%, \mathrm{v} / \mathrm{v}$, glycerol) at $30^{\circ} \mathrm{C}$. For nitrogen-starvation experiments, cells were pregrown on either YPD or YPG until mid-exponential phase and transferred to a medium containing $4 \%(\mathrm{w} / \mathrm{v})$ glucose or $5 \%(\mathrm{v} / \mathrm{v})$ glycerol and $0.167 \%$ (w/v) Difco Yeast Nitrogen Base without amino acids and without ammonium sulfate. This medium was renewed regularly in order to prevent depletion of the glucose and/or other nutrients.

Determination of survival. To estimate survival percentages, known quantities of cells were plated on YPD. After a few days of incubation at $30^{\circ} \mathrm{C}$, the number of colonies was counted and compared to the number of cells which had been plated. The initial survival ratio was always taken as $100 \%$.

Determination of CAMP and trehalose content, and invertase activity. For cAMP measurements, the cells were pre-incubated at $30^{\circ} \mathrm{C}$ for $10 \mathrm{~min}$ in $25 \mathrm{mM}$ MES buffer $\mathrm{pH} 6.0$ at a density of $30 \mathrm{mg} \mathrm{ml}^{-1}$. Samples were taken before and after addition of $100 \mathrm{mM}$ glucose. Extraction and determination of cAMP were performed as described previously (Thevelein et al., 1987). Extraction and determination of trehalose were carried out according to Neves et al. (1991). Invertase activity was determined by standard methods (Goldstein \& Lampen, 1975; Celenza \& Carlson, 1984) and protein by the Lowry procedure.

Flow cytometry. DNA content was determined by flow cytometry using propidium iodide as a DNA stain (Popolo et al., 1982).

Genetic analysis. Tetrad analysis was performed according to standard methods (Sherman et al., 1986).

Reproducibility of the results. All experiments were repeated at least three times. Representative results are shown.

\section{RESULTS}

Previous work has shown that the glucose-repression mutant $b \times k 2$ displays a glucose-induced cAMP signal also in exponential-phase glucose-grown cells, as opposed to wild-type cells, which only display such a signal when grown on nonfermentable carbon sources (Beullens et al., 1988). The results in Fig. 1 show that this is also true for the bex2 glucose-repression mutant. The absence or presence of the glucose-induced cAMP signal is not related to the activity of mitochondrial respiration, which is a glucose-repressible function, since addition of 10 p.p.m. antimycin A did not impair the cAMP response (results not shown). We have chosen the bex2 mutant for further studies on the physiological consequences of the constitutive character of glucose-induced activation of cAMP synthesis, because the sugar kinases, like hexokinase 2 , are themselves also involved in the generation of the cAMP signal (Beullens et al., 1988).

When cells of the bex 2 mutant and the corresponding wild-type strain were starved for nitrogen on a glucose-

Table 1. Saccharomyces cerevisiae strains used in this work

\begin{tabular}{|c|c|c|c|}
\hline Strain* & Relevant genotype & Complete genotype & Source \\
\hline SMC-19A & Wild-type; isogenic to SMC-1B/3 & $M A T \alpha$ leu1 $M A L 2-8^{c} M A L 3$ SUC3 & K. D. Entian \\
\hline SMC-1B & Wild-type; isogenic to $\mathrm{SMC}-1 \mathrm{~B} / 3$ & $M A T \mathbf{a}$ bis4 MAL2-8 $M A L 3$ SUC3 & K. D. Entian \\
\hline $\mathrm{SMC}-1 \mathrm{~B} / 3$ & bex2 & $M A T \mathbf{a}$ bex2 bis4 MAL2-8c MAL3 SUC3 & K. D. Entian \\
\hline FD11003 & Revertant of SMC-1B/3 & $M A T \mathbf{a}$ bis4 MAL2-8 $M A L 3$ SUC3 & This work \\
\hline FD11001 & bex2 shx & $\begin{array}{l}\text { MATa bex2 sbx bis } 4 \text { ura } 3 \triangle M A L 2-8^{c} M A L 3 \\
\quad \text { SUC3 }\end{array}$ & This work \\
\hline JS.cat $3-2 \mathrm{~A}$ & $\operatorname{cat} 3 / \operatorname{snf} 4$ & $M A \alpha$ leu2-3, 112 ura3-52 ade 1 cat3-37 MAL2-8c & K. D. Entian \\
\hline HRX.42-13C & cat1/snf1 & $\begin{array}{l}M A T \alpha \text { trp1 ade } 1 \text { bis4 cat } 1-42 M A L 2-8^{\circ} M A L 3 \\
\quad S U C 3\end{array}$ & K. D. Entian \\
\hline YSH371 & cat1/snf1s & 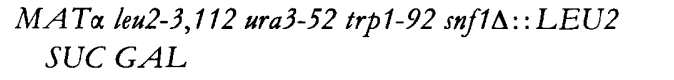 & S. Hohmann \\
\hline YM1871 & $g r r 1$ & 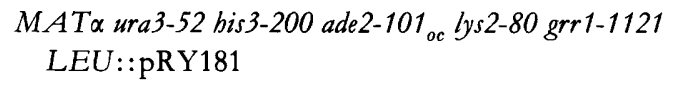 & M. Johnston \\
\hline YM2061 & Wild-type for YM1871 & $M A T \mathbf{a}$ ura3-52 bis 3-200 ade 2-101 oc lys2-801 & M. Johnston \\
\hline YM2953 & grr1 & $\begin{array}{l}\text { MATa ura3-52 bis 3-200 ade2-101 oc lys2-801 leu2-3,- } \\
\quad 112 \text { grr1:: LEU2 }\end{array}$ & M. Johnston \\
\hline YM2169 & Wild-type for YM2953 & MATa ura3-52 bis 3-200 ade2-101 oc lys2-801 & M. Johnston \\
\hline
\end{tabular}

* Strains SMC-19A, SMC-1B, SMC-1B/3, FD11003, FD11001, JS.cat3-2A and HRX.42-13C are congenic. Strains YM1871, YM2061, YM2953 and YM2169 are also congenic. 


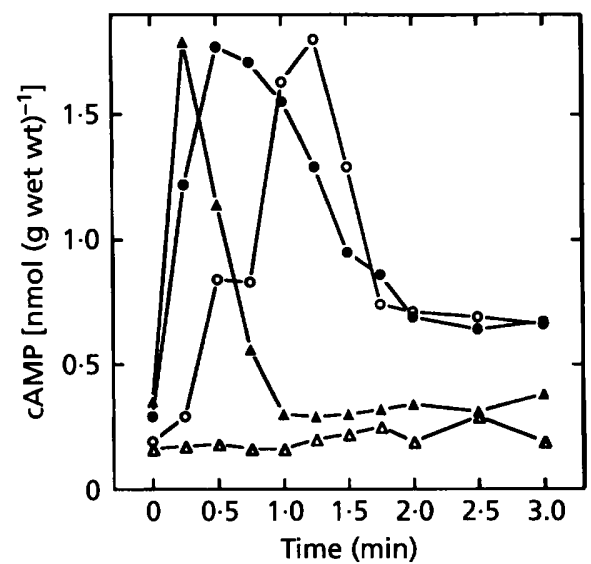

Fig. 1. Glucose-induced CAMP signal in exponential-phase cells of the glucose-repression mutant hex2 $(0,0)$ and the control strain $(\Delta, \triangle)$, grown either on glycerol $(\mathbf{O}, \Delta)$ or on glucose (O. $\triangle$ ).



Fig. 2. Viability during nitrogen starvation of the hex2 strain $(0, O)$, the spontaneous suppressor mutant hex 2 shx $(\square)$, and the control strain $(\Delta, \Delta) .0, \square, \triangle$, Glucose-containing medium;, $\boldsymbol{\Delta}$, glycerol-containing medium.

containing medium, viability dropped much faster in the bex2 mutant than in the wild-type strain (Fig. 2). This rapid drop in viability was not related to the presence of mitochondrial respiration in the hex 2 mutant (as opposed to the wild-type, where it is repressed by glucose) since it was not prevented by addition of 10 p.p.m. antimycin A (results not shown). On glycerol medium, the decrease in viability was slower in the bex 2 mutant, but this was also true in the wild-type strain (Fig. 2). In the course of these experiments, a spontaneous suppressor mutation $(s b x$, for suppressor of hex2) was isolated in the bex 2 strain which resulted in much better survival in particular during the first few days on glucose-containing nitrogen-starvation medium (Fig. 2). After a long starvation period this bex2 $s b x$ strain still showed somewhat lower survival than the wild-type (Fig. 2). Like the bex 2 strain, the hex 2 sh $x$ strain was unable to grow on medium containing maltose (not shown). Determination of starvation resistance in glycerol medium could not be performed with the bex 2 shx strain because it was unable to grow on glycerol (see below).

Subsequently, we measured by flow cytometry the ability of the bex 2 mutant to arrest in the $G_{1}$ phase of the cell cycle upon starvation for nitrogen in a glucose-containing medium. Whereas the cells of the control and bex $2 \operatorname{sh} x$ strain had shifted significantly in DNA content $4 \mathrm{~h}$ after the transfer and nearly completely $24 \mathrm{~h}$ after the transfer, the cells of the bex 2 mutant were clearly deficient in normal $G_{1}$ arrest (Fig. 3). Although the proportion of cells with a $1 \mathrm{C}$ DNA content had increased somewhat $24 \mathrm{~h}$ after transfer to nitrogen-starvation medium, the majority of the bex 2 cell population still showed a 2C DNA content. For another glucose-repression mutant, grr 1 , it has also been reported that it shows a greater loss of viability than the corresponding wild-type strain when starved for nitrogen on a glucose-containing medium (Flick \& Johnston, 1991). Flow cytometry measurements with two $g r r 1$ strains showed that both strains were also deficient in normal $G_{1}$ arrest under such conditions (results not shown). Previously, a mutant deficient in stationary-phase entry, whi2, was also found to be glucosederepressed (Mountain \& Sudbery, 1990).

The trehalose level in wild-type cells transferred to glucose-containing nitrogen-starvation medium showed a rapid and large increase during the initial days of starvation. Upon prolonged incubation in the same medium the trehalose was slowly mobilized again over a period of about 10-15 d (Fig. 4). In the bex 2 mutant initial trehalose accumulation was equally rapid and intensive but subsequent mobilization, on the other hand, was about as fast as the initial accumulation. Rather than taking $10-15 \mathrm{~d}$ as in the wild-type strain, all the trehalose was mobilized again in only $2-3 \mathrm{~d}$ (Fig. 4). The hex $2 \operatorname{sh} x$ strain accumulated much less trehalose than the other two strains during the first few days of nitrogen starvation (Fig. 4). Subsequently, when trehalose was mobilized again, there was a good correlation between remaining trehalose level (Fig. 4) and survival percentage (Fig. 2) in the three strains.

The suppressor mutation, shx, which spontaneously originated in the bex 2 strain and resulted in much better survival during starvation, has been characterized further. The double mutant hex $2 h x$ was unable to grow on the nonfermentable carbon sources glycerol, ethanol, pyruvate and raffinose, and it also did not grow on galactose (results not shown). While the bex2 mutant displayed a glucose-induced cAMP signal both in cells growing on glucose and in cells harvested at the time of glucose exhaustion, in neither of the two conditions did the bex2 $s h x$ strain show a glucose-induced cAMP signal (Fig. 5). Pretreatment with $5 \mathrm{mM}$ glucose before addition of $100 \mathrm{mM}$ glucose did not change these results (not shown), indicating that the cAMP increase in the bex2 cells harvested at the time of glucose exhaustion is not due to the combination of an initially low intracellular $\mathrm{pH}$ and a glucose-generated ATP increase (Argüelles et al., 1990). 

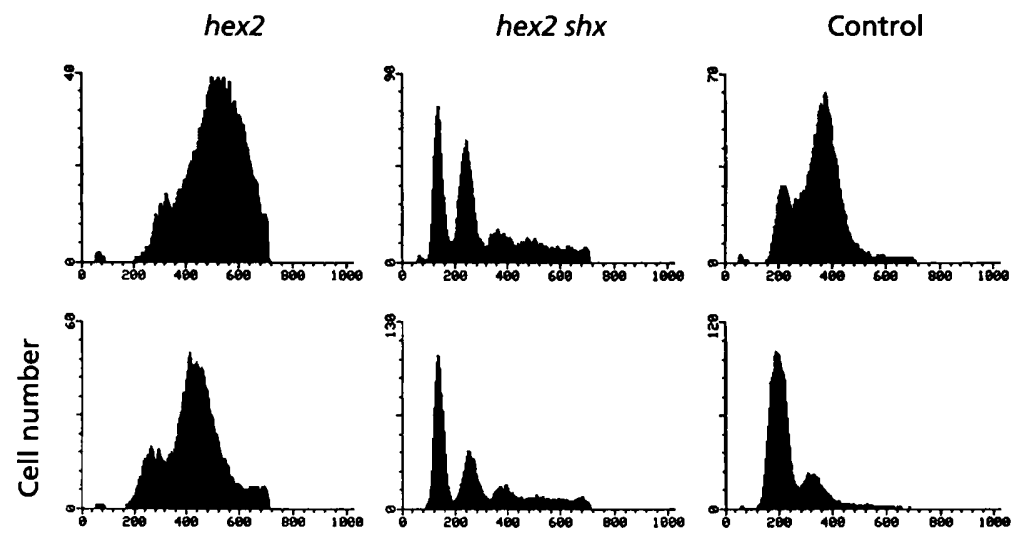

Fig. 3. Quantification of DNA content by flow cytometry during nitrogen starvation on glucose-containing medium of cells of the hex2 strain, the hex 2 shx strain and the
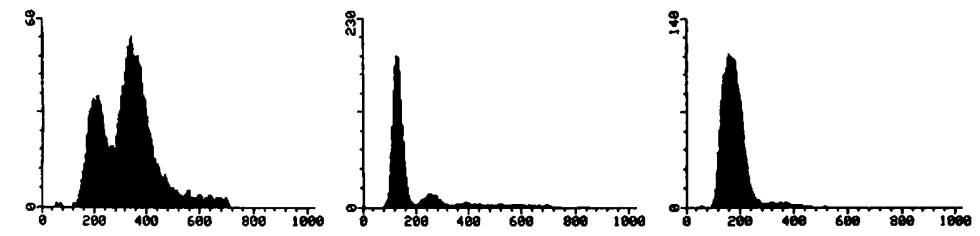

Relative DNA content control strain. The first peak represents cells with a 1CDNA content, the second peak cells with a 2C DNA content. Samples were taken at 0,4 and $24 \mathrm{~h}$ after transfer to nitrogen-starvation medium. Upper row, exponential-phase glucose-grown cells. Middle row, $4 \mathrm{~h}$, and lower row, $24 \mathrm{~h}$ after transfer to glucose-containing nitrogenstarvation medium.



Fig. 4. Trehalose content after transfer to glucose-containing nitrogen-starvation medium of cells of the glucose-repression mutant hex2 (O), the spontaneous suppressor mutant hex2 shx $(\square)$ and the control strain $(\triangle)$.

Since these results indicated that $s h x$ might be a derepression mutation like cat1/snf1 or cat $3 /$ snf4, we determined invertase activity in the bex $2 s b x$ mutant. In the control strain invertase activity was low in exponential phase on glucose and increased upon glucose exhaustion; in the be 2 mutant it was high in both conditions, while in the bex 2 sh $x$ strain it remained very low in both conditions (Table 2). These data confirmed that $s h x$ is a derepression mutation, epistatic to bex2. Complementation experiments with the bex2 sbx strain and cat1/snf1 and cat $3 /$ snf 4 strains showed that $s h x$ is a recessive mutation different from both these known derepression mutations (results not shown). Tetrad analysis of a diploid strain obtained by crossing the bex2 shx strain with a wild-type strain did not show a two-to-two segregation for the $s h x$-conferred

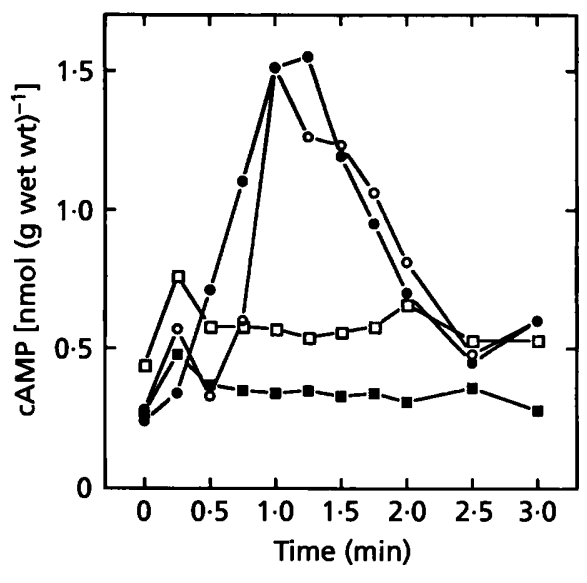

Fig. 5. Glucose-induced CAMP signal in exponential-phase glucose-grown cells $(\square, \square)$ and in cells harvested just after glucose exhaustion $(O, \square)$ of the glucose-repression mutant hex $2(0,0)$ and the spontaneous suppressor mutant hex 2 shx $(\square, \square)$.

inability to grow on nonfermentable carbon sources, indicating involvement of more than one mutation. Because of the difficulty in obtaining enough complete viable tetrads, further genetic analysis to determine the exact number of mutations involved was discontinued.

\section{DISCUSSION}

The absence of glucose-induced cAMP signalling in yeast cells growing on glucose could be explained in different ways: feedback-inhibition of cAMP synthesis, glucose receptor or glucose sensor desensitization, etc. The data presented in this paper provide new evidence for involvement of the glucose-repression pathway in down- 
Table 2. Invertase activity in the control, bex 2 and bex $2 s b x$ strains

\begin{tabular}{|c|c|c|c|}
\hline \multirow[t]{2}{*}{ Growth phase } & \multicolumn{3}{|c|}{$\begin{array}{c}\text { Invertase activity } \\
{\left[\text { nmol glucose liberated } \mathrm{min}^{-1}(\mathrm{mg} \text { protein })^{-1}\right]}\end{array}$} \\
\hline & Control & hex2 & $h e x 2 \operatorname{sh} x$ \\
\hline $\begin{array}{l}\text { Mid-exponential phase on } \\
\text { glucose medium (YDP) }\end{array}$ & 83 & 753 & 95 \\
\hline $\begin{array}{l}\text { Late exponential phase on } \\
\text { glucose medium (YPD) }\end{array}$ & 66 & 842 & 77 \\
\hline $\begin{array}{l}\text { Glucose just exhausted } \\
\text { in the same medium }\end{array}$ & 454 & 239 & 131 \\
\hline
\end{tabular}

regulating glucose-induced cAMP signalling in cells growing on glucose. The glucose-repression deficient mutant hex 2 shows constitutive glucose-induced cAMP signalling (Fig. 1) while the $s b x$ derepression mutation abolishes glucose-induced cAMP signalling, also in cells obtained under conditions in which wild-type cells have become derepressed (glucose just exhausted) (Fig. 5).

Downregulation of glucose-induced activation of cAMP synthesis might be important under conditions in which ample glucose is present but where growth is impaired or prevented due to shortage or deficiency, respectively, of one or more other essential nutrients. Such conditions are likely to occur in grape juice, a common natural habitat of yeast, where glucose concentrations in the range 1-2 M are typical (Bisson et al., 1993). Reduction of the growth rate or entrance into the stationary-phase $G_{0}$ are well known to be associated with increases in the level of trehalose and glycogen, with enhanced expression of e.g. heat-shock proteins and catalase, and with a general increase in stress resistance (Werner-Washburne et al., 1993). All these properties are counteracted by an elevated cAMP level or elevated activity of cAMP-dependent protein kinase. In addition, a high cAMP level or high activity of cAMP-dependent protein kinase also causes inability to arrest properly at the start point in the $G_{1}$ phase of the cell cycle (Matsumoto et al., 1983; Toda et al., 1985). Therefore, continuous glucose-induced stimulation of the Ras-adenylate cyclase pathway might be injurious to proper $G_{1}$ arrest and proper acquisition of $G_{0}$ characteristics.

Our results support this idea. Incubation of the bex2 mutant on nitrogen-starvation medium containing ample glucose prevents proper $G_{1}$ arrest (Fig. 3) and proper maintenance of trehalose (Fig. 4), and results in rapid loss of viability (Fig. 2). A strong argument that the glucoserepression defect is responsible for the rapid loss of viability on glucose-containing nitrogen-starvation medium is the isolation of the spontaneous epistatic derepression mutation $s b x$ which caused much better survival (Fig. 2) without suppression of other characteristics of the pleiotropic bex2 phenotype. Glucoseinduced cAMP signalling (Fig. 5) and derepression of invertase (Table 2) were both abolished by the $\operatorname{shx}$ mutation, supporting the connection between constitutive derepression, constitutive glucose-induced cAMP signalling and loss of viability. $G_{1}$ arrest (Fig. 3) and trehalose maintenance (Fig. 4) were also largely restored by the derepression mutation, supporting the idea that their deficiency in the bex 2 mutant was also due to the defect in glucose repression.

On glycerol medium the loss of viability was clearly reduced but this was also observed with the wild-type, where the difference between glucose and glycerol was at least as large as in the bex2 mutant (Fig. 2). However, in addition to its glucose repression deficiency the bex2 mutant has a pleiotropic phenotype. It also displays higher hexokinase activity. Hence, it cannot be excluded that in cells grown on a nonfermentable carbon source like glycerol the glucose-repressible protein might be present in a higher level in bex 2 cells compared to wildtype cells. Such overexpression would then abolish any relative improvement in viability the bex 2 mutant might have when grown on glycerol compared to glucose, because the higher level of the glucose-repressible protein would in this case cause overstimulation of cAMP synthesis.

In conclusion, our results suggest that the glucoserepressible character of glucose-triggered activation of cAMP synthesis serves to prevent overstimulation of the Ras-cAMP pathway under conditions in which ample glucose is present and another nutrient is restricting growth. In the natural environment of $S$. cerevisiae such conditions might be very common. Under such conditions the cells should be able to arrest at the start point of the cell cycle and to enter the $G_{0}$ phase. Arrest at start and acquisition of the physiological characteristics typical of $\mathrm{G}_{0}$ is known to be counteracted by high cAMP levels. Glucose repression of the pathway involved in glucosetriggered activation of cAMP synthesis allows the cells to acquire all characteristics typical of cells with a low cAMP level in the presence of an excess of glucose. Our results therefore provide further support that the function of glucose-triggered activation of the Ras-cAMP pathway is limited to the transition between the gluconeogenicrespiratory and the fermentative growth mode and that 
the 'high protein kinase A phenotype' of cells growing on glucose is not due to continuous glucose-triggered stimulation of the Ras-cAMP pathway. In cells growing exponentially on glucose, a novel pathway, not activated by glucose alone but rather by a complete glucosecontaining growth medium, is in our view responsible for the 'high protein kinase A phenotype', presumably by direct activation of the free catalytic subunits of protein kinase A. Exhaustion of whatever essential nutrient in the medium and also exhaustion of the glucose in the medium shuts off this fermentable-growth-medium-induced pathway and at the same time results in loss of the 'high protein kinase A phenotype'. As a result both cells growing on non-fermentable carbon sources and stationary-phase cells, including those in a medium with ample glucose present but another nutrient lacking, display a 'low protein kinase A phenotype'.

\section{ACKNOWLEDGEMENTS}

We wish to thank K. D. Entian (University of Frankfurt, FRG), M. Johnston (Washington University Medical School) and S. Hohmann for kind provision of yeast strains, and W. Verheyden for excellent technical assistance. J.C. A. was on leave from the University of Murcia (Spain) as postdoctoral fellow of the Spanish Ministry for Education and Science (plan FPI). This work was supported by grants from the Belgian National Fund for Scientific Research (FGWO), the Belgian National Lottery, the Research Fund of the KU Leuven, the Flemish Biotechnology Action Programme (VLAB/054 and VLAB/TOP041 ) and the European Commission (HC\&M CHRXCT93-0265).

\section{References}

Arguielles, J. C., Mbonyi, K., Van Aelst, L., Vanhalewyn, M., Jans, A. W. H. \& Thevelein, J. M. (1990). Absence of glucose-induced cAMP signaling in the Saccharomyces cerevisiae mutants cat 1 and cat 3 which are deficient in derepression of glucose-repressible proteins. Arch Microbiol 154, 199-205.

Belazzi, T., Wagner, A., Wieser, R., Schanz, M., Adam, G., Hartig, A. \& Ruis, H. (1991). Negative regulation of transcription of the Saccharomyces cerevisiae catalase T (CTT1) gene by cAMP is mediated by a positive control element. EMBO J 10, 585-592.

Beullens, M., Mbonyi, K., Geerts, L., Gladines, D., Detremerie, K., Jans, A. W. H. \& Thevelein, J. M. (1988). Studies on the mechanism of the glucose-induced cAMP-signal in glycolysis- and glucose repression-mutants of the yeast Saccharomyces cerevisiae. Eur J Biochem 172, 227-231.

Bissinger, P. H., Wieser, R., Hamilton, B. \& Ruis, H. (1989). Control of Saccharomyces cerevisiae catalase $T$ gene (CTT1) expression by nutrient supply via the RAS-cyclic AMP pathway. Mol Cell Biol 9, 1309-1315.

Bisson, L. F., Coons, D. M., Kruckeberg, A. L. \& Lewis, D. A. (1993). Yeast sugar transporters. Crit Rev Biochem Mol Biol 28, 259-308.

Broach, J. R. \& Deschenes, R. J. (1990). The function of $R A S$ genes in Saccharomyces cerevisiae. Adv Cancer Res 54, 79-139.

Cameron, S., Levin, L., Zoller, M. \& Wigler, M. (1988). cAMPindependent control of sporulation, glycogen metabolism, and heat shock resistance in S. cerevisiae. Cell 53, 555-566.
Camonis, J. H., Kalékine, M., Gondré, B., Garreau, H., BoyMarcotte, E. \& Jacquet, M. (1986). Characterization, cloning and sequence analysis of the CDC25 gene which controls the cyclic AMP level of Saccharomyces cerevisiae. EMBO J 5, 375-380.

Celenza, J. L. \& Carlson, M. (1984). Cloning and genetic mapping of $S N F 1$, a gene required for expression of glucose-repressible genes in Saccharomyces cerevisiae. Mol Cell Biol 4, 49-53.

Durnez, P., Pernambuco, M. B., Oris, E., Argúelles, J.-C., Mergelsberg, H. \& Thevelein, J. M. (1994). Activation of trehalase during growth induction by nitrogen sources in the yeast Saccharomyces cerevisiae depends on the free catalytic subunits of cAMP-dependent protein kinase. Yeast 10, 1049-1064.

Entian, K.-D. (1980). A defect in carbon catabolite repression associated with uncontrollable and excessive maltose uptake. Mol \& Gen Genet 179, 169-175.

Entian, K.-D. \& Barnett, J. A. (1992). Regulation of sugar utilization by Saccharomyces cerevisiae. Trends Biochem Sci 17, 506-510.

Flick, J. S. \& Johnston, M. (1991). GRR1 of Saccharomyces cerevisiae is required for glucose repression and encodes a protein with leucine-rich repeats. Mol Cell Biol 11, 5101-5112.

Goldstein, A. \& Lampen, O. (1975). $\beta$-D-Fructofuranoside fructohydrolase from yeast. Methods Enzymol 42C, 504-511.

Hirimburegama, K., Durnez, P., Keleman, J., Oris, E., Vergauwen, R., Mergelsberg, H. \& Thevelein, J. M. (1992). Nutrient-induced activation of trehalase in nutrient-starved cells of the yeast Saccharomyces cerevisiae. cAMP is not involved as second messenger. $J$ Gen Microbiol 138, 2035-2043.

Johnston, M. \& Carlson, M. (1992). Regulation of carbon and phosphate utilization. In The Molecular and Cellular Biology of the Yeast Saccharomyces, vol. 2, Gene Expression, pp. 193-281. Edited by E. W. Jones, J. R. Pringle \& J. R. Broach. Cold Spring Harbor, NY: Cold Spring Harbor Laboratory.

Lillie, S. H. \& Pringle, J. R. (1980). Reserve carbohydrate metabolism in Saccharomyces cerevisiae. Response to nutrient limitation. J Bacteriol 143, 1384-1394

Matsumoto, K., Uno, I. \& Ishikawa, T. (1983). Control of cell division in Saccharomyces cerevisiae mutants defective in adenylate cyclase and cAMP-dependent protein kinase. Exp Cell Res 146, 151-161.

Mbonyi, K., Beullens, M., Detremerie, K., Geerts, L. \& Thevelein, J. M. (1988). Requirement of one functional $R A S$ gene and inability of an oncogenic ras-variant to mediate the glucose-induced cAMP signal in the yeast Saccharomyces cerevisiae. Mol Cell Biol 8, 3051-3057.

Mountain, H. A. \& Sudbery, P. E. (1990). The relationship of growth rate and catabolite repression with WHI2 expression and cell size in Saccharomyces cerevisiae. J Gen Microbiol 136, 733-737.

Neves, M. J., Jorge, J. A., François, J. M. \& Terenzi, H. F. (1991). Effects of heat shock on the level of trehalose and glycogen, and on the induction of thermotolerance in Neurospora crassa. FEBS Lett 283, 19-22.

Niederacher, D. \& Entian, K. D. (1991). Characterization of Hex2 protein, a negative regulatory element necessary for glucose repression in yeast. Eur J Biochem 200, 311-319.

Nikawa, J., Cameron, S., Toda, T., Ferguson, K. W. \& Wigler, M. (1987a). Rigorous feedback control of cAMP levels in Saccharomyces cerevisiae. Genes \& Dev 1, 931-937.

Nikawa, J., Sass, P. \& Wigler, M. (1987b). Cloning and characterization of the low-affinity cyclic AMP phosphodiesterase gene of Saccharomyces cerevisiae. Mol Cell Biol 7, 3629-3636.

Popolo, L., Vanoni, M. \& Alberghina, L. (1982). Control of the yeast cell cycle by protein synthesis. Exp Cell Res 142, 69-78. 
Sass, P., Field, J., Nikawa, J., Toda, T. \& Wigler, M. (1986). Cloning and characterization of the high-affinity cAMP phosphodiesterase of S. cerevisiae. Proc Natl Acad Sci US A 83, 9303-9307.

Sherman, F., Fink, G. R. \& Hicks, J. B. (1986). Laboratory Course Manual for Methods in Yeast Genetics. Cold Spring Harbor, NY : Cold Spring Harbor Laboratory.

Tanaka, K., Matsumoto, K. \& Toh-e, A. (1989). Ira1, an inhibitory regulator of the RAS-cyclic AMP pathway in Saccharomyces cerevisiae. Mol Cell Biol 9, 757-768.

Tanaka, K., Nakafuku, M., Tamanoi, F., Kaziro, Y., Matsumoto, K. \& Toh-e, A. (1990). IR A2, a second gene of Saccharomyces cerevisiae that encodes a protein with a domain homologous to mammalian Ras GTPase-activating protein. Mol Cell Biol 10, 4303-4313.

Tatchell, K. (1993). $R A S$ genes in the budding yeast Saccharomyces cerevisiae. In Signal Transduction. Prokaryotic and Simple Eukaryotic Systems, pp. 147-188. Edited by J. Kurjan \& B. L. Taylor. San Diego: Academic Press.

Thevelein, J. M. (1991). Fermentable sugars and intracellular acidification as specific activators of the RAS-adenylate cyclase signalling pathway in yeast: the relationship to nutrient-induced cell cycle control. Mol Microbiol 5, 1301-1307.

Thevelein, J. M. (1992). The RAS-adenylate cyclase pathway and cell cycle control in Saccharomyces cerevisiae. Antonie Leeuwenboek 62, 109-130.

Thevelein, J. M. \& Beullens, M. (1985). Cyclic AMP and the stimulation of trehalase activity in the yeast Saccharomyces cerevisiae by carbon sources, nitrogen sources and inhibitors of protein synthesis. J Gen Microbiol 131, 3199-3209.
Thevelein, J. M. \& Hohmann, S. (1995). Trehalose synthase: guard to the gate of glycolysis in yeast? Trends Biochem Sci 20, 3-10.

Thevelein, J. M., Beullens, M., Honshoven, F., Hoebeeck, G., Detremerie, K., Den Hollander, J. A. \& Jans, A. W. H. (1987). Regulation of the cAMP level in the yeast Saccharomyces cerevisiae: intracellular $\mathrm{pH}$ and the effect of membrane depolarizing compounds. J Gen Microbiol 133, 2191-2196.

Toda, T., Uno, I., Ishikawa, T., Powers, S., Kataoka, T., Broek, D., Cameron, S., Broach, J., Matsumoto, K. \& Wigler, M. (1985). In yeast, Ras proteins are controlling elements of adenylate cyclase. Cell 40, 27-36.

Toda, T., Cameron, S., Sass, P., Zoller, M., Scott, J. D., McBullen, B., Hurwitz, M., Krebs, E. G. \& Wigler, M. (1987a). Cloning and characterization of $B C Y 1$, a locus encoding a regulatory subunit of the cyclic AMP-dependent protein kinase in Saccharomyces cerevisiae. Mol Cell Biol $7,1371-1377$.

Toda, T., Cameron, S., Sass, P., Zoller, M. \& Wigler, M. (1987b). Three different genes in Saccharomyces cerevisiae encode the catalytic subunits of the cAMP-dependent protein kinase. Cell 50, 277-287.

Tung, K.-S., Norbeck, L. L., Nolan, S. L., Atkinson, N. S. \& Hopper, A. K. (1992). $S R N 1$, a yeast gene involved in RNA processing, is identical to $H E X 2 / R E G 1$, a negative regulator in glucose repression. Mol Cell Biol 12, 2673-2680.

Werner-Washburne, M., Braun, E., Johnston, G. C. \& Singer, R. A. (1993). Stationary phase in the yeast Saccharomyces cerevisiae. Microbiol Rev 57, 383-401.

Received 18 January 1995; accepted 22 March 1995. 